\title{
Association Between the SLCIAI Glutamate Transporter Gene and Obsessive-Compulsive Disorder in the Chinese Han Population
}

This article was published in the following Dove Press journal: Neuropsychiatric Disease and Treatment

\author{
Xing Huang' \\ Jie Liu $^{2}$ \\ Jinzhi Cong ${ }^{3}$ \\ Xinhua Zhang $\mathbb{D}^{\prime}$ \\ 'Department of Psychology and \\ Psychiatry, Medical College, Qingdao \\ University, Qingdao, People's Republic of \\ China; ${ }^{2}$ Department of Psychiatry, \\ Qingdao Mental Health Center, Qingdao, \\ People's Republic of China; ${ }^{3}$ Health \\ Convergence Media Communication \\ Division, Shandong Health Publicity and \\ Education Center, Jinan, People's \\ Republic of China
}

Correspondence: Xinhua Zhang Department of Psychology and Psychiatry, Medical College, Qingdao University, 38 Dengzhou Road, Qingdao, 26602I, People's Republic of China

Tel +865328279 0547

Fax +8653282911385

Email xhzhang87@126.com
Background: Obsessive-compulsive disorder (OCD) is a common, serious and genetically related mental illness; the etiology of OCD has not yet reached a definitive conclusion. Multiple evidence suggests that the glutamatergic system plays a major role in the pathophysiology of OCD. However, subsequent studies on the glutamate transporter gene are not consistent. OCD is a heterogeneous disease. To resolve the complex genetic basis of OCD, division the disorder into different subphenotypes is an effective method for studying the pathogenesis of OCD.

Methods: We recruited 438 OCD patients and 465 age- and sex-matched controls from a Chinese Han population. rs 10491734, rs3780412, rs301434 and rs3087879 SNPs were genotyped by real-time TaqMan polymerase chain reaction, and the chi-squared test was used to compare allele and genotype frequencies of variants between the two groups.

Results: The genotype of $r s 301434$ was statistically significant in total patients with OCD and the controls. After grouping by age and gender, the genotype of $r s 301434$ was statistically significant in early-onset OCD, late-onset OCD as well as male OCD, the allele and genotype of $r s 3780412$ was associated with late-onset OCD. Haplotype analysis showed that four loci haplotypes (G-A-A-G and G-G-A-G) were associated with total OCD, (G-G-A-G) was associated with female OCD, (G-A-G-G) was associated with male OCD, (G-A-A-G and G-G-A-G) were associated with late-onset OCD.

Conclusion: This study provides suggestive evidence that SLC1A1 may be involved in the development of OCD in the Han population. However, these findings require further replication.

Keywords: obsessive-compulsive disorder, glutamate transporter gene, haplotype

\section{Introduction}

Obsessive-compulsive disorder (OCD) is a common mental illness with complicated clinical symptoms. The disease is characterized by intrusive unwanted thoughts and repetitive behavior. The lifetime prevalence of patients is between $1 \%$ and $3 \%$, and it is listed as one of the ten most disabling diseases in the world by the World Health Organization (WHO). ${ }^{1,2}$ OCD is often accompanied by other mental illnesses, such as Tourette's syndrome or eating disorders, which makes treatment more difficult. ${ }^{3,4}$

More and more evidences show that the glutamatergic system plays an important role in the etiology and subsequent treatment of OCD. ${ }^{5}$ Imaging and biological studies have shown that glutamate dysregulated neurotransmission in special parts 
of the brain leads to the appearance of OCD symptoms. ${ }^{6}$ According to multiple independent family-based association studies and a case-control analysis, the SLC1A1 gene is closely related to the occurrence of OCD. ${ }^{7-9}$ Studies have pointed out that compared with the control group, the concentration of glutamate in the cerebrospinal fluid of OCD patients is higher. ${ }^{10}$ And the abnormal glutamatergic transmission in the cortex-striatum-thalamus-cortex (CSTC) circuit plays a certain role in the pathogenesis of OCD. ${ }^{11}$ In addition, it has been observed that children with OCD a decreased amount of glutamate in the anterior cingulate cortex. In the brain regions of patients with OCD, the level of glutamate receptors is also modified. It has been reported that serotonin can affect dopaminergic activity indirectly through the glutamatergic and GABAergic systems. ${ }^{12}$ It has been reported that serotonin can influence dopaminergic activity indirectly through the glutamatergic and GABA-ergic systems. ${ }^{13}$

SLC1A1 is located on chromosome 9p24, which is expressed in brain regions related to $\mathrm{OCD},{ }^{14}$ including the cerebral cortex, striatum, and thalamus. ${ }^{15} \mathrm{As}$ research into the hereditary pattern of OCD increases, the role of the glutamate transporter gene SLC1A1 in the pathogenesis of the disease has attracted attention. ${ }^{9,16-18}$ The glutamate transporter EAAC1 (EAAT3) is a crucial transporter for mammals. Approximately $30-40 \%$ of synapses in the mammalian brain are affected by EAAC1, which is encoded by SLC1A1 gene. ${ }^{19}$ Bellini et al found that mice lacking EAAC1 showed increased anxiety-like and disrupted grooming behaviors, and then they identify new molecular mechanisms by which EAAC1 can shape glutamatergic and dopaminergic signals and control repeated movement execution. ${ }^{20}$ An important function of EAAC1 is to stop the postsynaptic effects of glutamate as well as to regulate extrasynaptic glutamate levels, thus limiting the activation of extra-synaptic neurotransmitter receptors by rapidly removing released glutamate from the synaptic cleft and so alleviating subsequent excitotoxicity. EAAC1 enables excitatory transmission between synapses to function correctly. The SLC1A1 gene polymorphisms may be factors which contribute to glutamate dysfunction in cases of OCD.

It has been speculated that genetic variation within or near the SLC1A1 gene is associated with OCD in the Chinese Han population. OCD is a complex disease, in which patients with early-onset OCD and patients with late-onset OCD have different genetic foundations and clinical symptoms, which makes their treatment results often different. We classified the onset-age $<18$ as earlyonset and the onset-age $\geq 18$ as late-onset in the present study. We aimed to provide basic evidence for SLC1A1 as a candidate gene for the etiology of OCD in this population. A total of 438 OCD patients and 465 healthy controls were genotyped, and four SNPs (rs 10491734, rs3780412, rs301434 and rs3087879) were selected to validate our hypothesis.

\section{Materials and Methods Case Control Sample}

A total of 438 OCD patients (mean age, 29.27 \pm 13.96 years) and 465 controls (mean age, 28.77 \pm 9.25 years) from the Affiliated Hospital of Medical College Qingdao University participated in this study. All subjects provided written informed consent, children in the present study were written and provided by their guardians. The OCD patient group included 260 male patients and 178 female patients, while the control group comprised 276 male subjects and 189 female subjects. We diagnosed patients according to the criteria of the Diagnostic and Statistical Manual of mental disorders (DSM-IV) and Obsessive compulsive symptoms of participants were assessed through the Yale-Brown Obsessive Compulsive Scale Checklist (YBOCS-CL), ${ }^{21}$ indicating that all patients were severely affected $(26.72$ \pm 4.43 ). YBOCS severity scale scores range from 0 to 40 , with a score $\geq 16$, indicating clinically significant symptoms. A score of $\geq 16$ on the YBOCS severity scale was required for inclusion in this study. Subjects with a diagnosis, according to DSM-IV, of schizophrenia, recurrent major depression, bipolar disorder, mental retardation, alcohol or other substance abuse within the last 6 months or a history of psychosurgery, encephalitis, or significant head trauma were excluded. Subjects showing slight OCD symptoms with serious comorbidity symptoms, such as anxiety, depression and tic, were also excluded. Subjects refusing to participate or permit the extraction of venous blood were excluded.

Healthy control $(n=465)$ subjects were recruited from the Center of Health Examination of the Affiliated Hospital of Qingdao University Medical College. All controls were included after being interviewed using the Diagnostic Interview for Genetic Studies ${ }^{22}$ and Family Interview for Genetic Studies (assessing firstdegree relatives of control families according to the 
reports of controls) to confirm the absence of both personal and familial history of OCD and other psychiatric disorders. Two experienced psychiatrists conducted a MINI for each member of the control samples to ensure that none of the controls suffered from any psychiatric disorders before beginning the current study.

The protocol of this study conformed to the ethical guidelines of the 1975 Declaration of Helsinki. This study was approved through the Ethics Committees of Affiliated Hospital of Qingdao University Medical College. All subjects provided written informed consent. In particular, the informed consent for children in the present study was written and provided by their guardians.

\section{DNA Analysis and Statistical Analysis}

Genomic DNA was extracted from leukocytes in the peripheral blood using standard methods. DNA amplification was conducted using polymerase chain reaction (PCR). The following PCR primer sequences were used: rs301434 forward, 5-ACGTTGGATGGCCCTGAAAAATCCCTTGAC-3, and rs301434 reverse, 5-ACGTTGGATGCAAGGGCAAG GACTTGTCTC-3; rs3780412 forward, 5-ACGTTGGA TGAGCCCCCACAAAATACTCTG-3, and rs3780412 reverse, 5-ACGTTGGATGGAAGAGGTTTTATGTTTG TC-3; rs10491734 forward, 5-ACGTTGGATGGGAGA CTTTGACTTTGCCAC-3, and rs10491734 reverse, 5-ACGTTGGATGCTTTTTGTTTCTGAATGCCC-3; rs3087879 forward, 5-ACGTTGGATGTGCAGAGT AAATCCCACGAC-3, and rs3087879 reverse, 5ACGTTGGATGGGAGGAGACAAGAGTCATAG-3. PCR was performed in a final volume of $5 \mu \mathrm{L}$ containing $1 \mu \mathrm{L}$ of genomic DNA, $0.95 \mu \mathrm{L}$ of $\mathrm{H}_{2} \mathrm{O}, 0.625 \mu \mathrm{L}$ of PCR Buffer (10×), $0.325 \mu \mathrm{L}$ of $\mathrm{Mg} \mathrm{Cl}_{2}(25 \mathrm{mM}), 1 \mu \mathrm{L}$ of dNTP $(2.5 \mathrm{mM}$ each), $1 \mu \mathrm{L}$ of primer, and $0.1 \mu \mathrm{L}$ of HotStarTaq DNA Polymerase $(5 \mathrm{U} / \mu \mathrm{L})$. The following cycling conditions were used: initial denaturation at $94^{\circ} \mathrm{C}$ for $15 \mathrm{~min}$, followed by 45 cycles at $94^{\circ} \mathrm{C}$ for $20 \mathrm{~s}, 56^{\circ} \mathrm{C}$ for $30 \mathrm{~s}$, and $72^{\circ} \mathrm{C}$ for 1 min, with a final extension at $72^{\circ} \mathrm{C}$ for $3 \mathrm{~min}$ and storage at $4^{\circ}$ C. Subsequently, we added the SAP reaction mix (final volume of $2 \mu \mathrm{L}$ ), containing $1.53 \mu \mathrm{L}$ of $\mathrm{H}_{2} \mathrm{O}, 0.17 \mu \mathrm{L}$ of SAP Buffer $(10 \times)$, and $0.3 \mu \mathrm{L}$ of SAP enzyme $(1 \mathrm{U} / \mu \mathrm{L})$, to the PCR product. The reaction was initiated at $37^{\circ} \mathrm{C}$ for 40 min, followed by incubation at $85^{\circ} \mathrm{C}$ for $5 \mathrm{~min}$. The reaction was maintained at $4^{\circ} \mathrm{C}$. iPlex reagent (Sequenom, San Diego, CA) (final volume of $2 \mu \mathrm{L}$, containing $0.755 \mu \mathrm{L}$ of $\mathrm{H}_{2} \mathrm{O}, 0.2$ $\mu \mathrm{L}$ of iPlex Buffer $(10 \times), 0.2 \mu \mathrm{L}$ of iPlex Termination mix, and $0.041 \mu \mathrm{L}$ of iPlex enzyme) was then added to the reaction product. The following cycling conditions were used: $94^{\circ} \mathrm{C}$ for $30 \mathrm{~s}$, followed by 40 cycles at $94^{\circ} \mathrm{C}$ for $5 \mathrm{~s}$, five cycles at $52^{\circ} \mathrm{C}$ for $5 \mathrm{~s}$, and $80^{\circ} \mathrm{C}$ for $5 \mathrm{~s}$, with a final extension at $72^{\circ} \mathrm{C}$ for $3 \mathrm{~min}$ and storage at $4^{\circ} \mathrm{C}$.

Following purification, the reaction product was analyzed using MassARRAY SpectroCHIP (Sequenom, San Diego, CA). SNPs were detected with a MassARRAY Compact Analyzer (Sequenom, San Diego, CA). Results were analyzed using TYPER software (Sequenom, San Diego, CA) and genotyping data were obtained. Detection accuracy was $99.6 \%$. SNP genotyping was performed at Shanghai Benegene Biotechnologies Co. Ltd., and data analysis was conducted using SPSS software (version 17.0 for Windows; SPSS, Inc., Chicago, IL, USA). Age comparisons between the OCD and control groups were made with a $t$-test. Allelic, genotypic and haplotype frequencies between OCD participants and controls, as well as to estimate the Hardy-Weinberg equilibrium were established by SHEsis software (http:// $\underline{\text { analysis.bio-x.cn). }} .^{23}$

\section{Results}

No deviation of the Hardy-Weinberg equilibrium was found in the distribution of the four SNPs among OCD and control groups $(\mathrm{P}>0.05)$. We found significant differences in genotype frequencies of rs301434 between all OCD and control groups, while there were significant differences in genotype frequency of $r s 301434$ between early-onset OCD and control groups, lateonset OCD and control groups as well as male OCD and control groups (total $\chi 2=9.948, \mathrm{P}=0.007$; male $\chi 2=8.766, \mathrm{P}=0.013$; female $\chi 2=2.331, \mathrm{P}=0.311$; earlyonset $\quad \chi^{2}=8.982, \quad \mathrm{P}=0.011 ; \quad$ late-onset $\quad \chi 2=8.839$, $\mathrm{P}=0.012$ ).

We also found that genotype and allele frequencies of $r s 3780412$ were statistically significant for the late-onset OCD and control groups (genotype $\chi 2=7.196, \mathrm{P}=0.027$; allele $\chi 2=5.575, \mathrm{P}=0.018$ ). However, we found that genotype and allele frequencies of rs 10491734 and $r s 3087879$ were not statistically significant for OCD or control groups.

Four loci haplotypes (rs10491734-rs3780412rs301434-rs3087879) were found to be associated with OCD. Haplotypes G-A-A-G and G-G-A-G were statistically significant for all OCD and control groups $(\mathrm{P}=0.033$ and 0.030 , respectively). Haplotype 
G-A-G-G was associated with the male OCD group $(\mathrm{P}=0.010)$, while $\mathrm{G}-\mathrm{G}-\mathrm{A}-\mathrm{G}$ was associated with the female OCD group $(\mathrm{P}=0.039)$. Finally, we found that G-A-A-G, G-G-A-G were associated with the lateonset OCD groups ( $\mathrm{P}=0.019$ and 0.050 , respectively). In addition, our use of haplotype analysis showed that $\mathrm{G}-\mathrm{A}-\mathrm{G}-\mathrm{G}$ is a risk factor for male $\mathrm{OCD}(\mathrm{OR}=1.737$, 95\% CI: $1.134-2.660$ ), while G-G-A-G is a risk factor for total $(\mathrm{OR}=1.412,95 \% \mathrm{CI}: 1.033-1.930)$, female $(\mathrm{OR}=1.670,95 \% \mathrm{CI}: 1.021-2.730)$ and late-onset $\mathrm{OCD}$ $(\mathrm{OR}=1.469,95 \%$ CI: 0.997-2.166).

\section{Discussion}

Obsessive-compulsive disorder is a complex multifactorial disease, which seems to be affected by environmental and genetic factors. Recent reports indicate that glutamate transporter gene mutations play a role in the etiology of OCD. Our study found significant differences in genotype frequencies of $r s 301434$ between total OCD group and control group. After grouping by gender and age, the results indicate a significant difference in the genotype frequency of $r s 301434$ between early-onset OCD and control groups, late-onset OCD and control groups as well as male OCD and control groups (See Table 2). Arnold et al found that two variants located within a single haplotype block, rs301434 and rs301435, were associated with the transmission of $\mathrm{OCD},{ }^{7}$ while de Salles Andrade and colleagues found that the A-A-G (rs301434-rs3780412-rs301443) haplotype was twice as common for people with OCD than for controls. Regarding clinical characteristics, the G-A (rs301434rs3780412) haplotype in patients with OCD seems to be related to the symptoms of hoarding. ${ }^{24}$ This finding implicated that $r s 301434$ may be an important SNP to OCD in the Han Chinese population. Rs301434 may influence the development of OCD through expression of the neuronal glutamate transporter.

Dickel et al found a positive relationship between rs3780412, rs301430 and OCD, where the association is limited to males in $r s 3780412 .^{\circ}$ Wendland et al found three highly significant synthetic markers in haplotype analysis, where rs3087879, rs301430 and rs3858819 were significant in the OCD haplotype test. ${ }^{9}$ When we tested $r s 3780412$ and rs3087879 in the Han population, we found a significant difference in allele and genotype frequency of $r s 3780412$ between late-onset OCD and control groups. However, genotypes and alleles of $r s 3087879$ were not statistically significant between OCD patients and control groups, nor between the stratified groups (See Tables 1 and 2). The further research significance of dividing OCD into early and late subtypes lies in exploring the genetic and neurobiological determinants of OCD and predicting the best treatment plan. The symptoms of OCD are heterogeneous and are thought to emerge from complex genetic, environmental, and epigenetic interactions. Compared with late-onset OCD, early-onset OCD are more likely to be associated with Tourette syndrome, have greater heritability, and have more difficult treatment. We speculate that late-onset OCD may be related to $r s 3780412$, which may have connection with the influence of psychosocial factors on patients. Certain social factors may have an impact on this SNP, which is expressed in patients with late-onset OCD. We will make further analysis of related influencing factors in future research.

Some authors have found that 3-SNP haplotype rs4740788-rs10491734-rs10491735 was associated with a total sample of OCD patients as well as with male OCD. ${ }^{16} \mathrm{Wu}$ and colleagues found that $r$ s 10491734 was significantly associated with early-onset OCD ${ }^{25}$ However, we did not reach this conclusion for the Han population (See Tables 1 and 2). This may be due to the polymorphism of the locus.

Although we only found positive results in the two SNPs rs301434 and rs3780412, haplotypes studies found more positive results, which may be due to polymorphisms at multiple loci alleles affect different subtypes of OCD and clinical symptoms (See Table 1). We found that haplotypes of the four SNPs (rs10491734rs3780412-rs301434-rs3087879) showed significant differences between the OCD and control groups as a whole. After classifying OCD participants on the basis of sex and age, we found significant differences between male OCD and controls, female OCD and controls as well as late-onset OCD and controls. The haplotype G-A-A-G was associated with both total OCD and late-onset OCD. Haplotype G-A-G-G was associated with male OCD and is a risk factor for male OCD. Haplotype G-G-A-G was associated with total OCD, female OCD and late-onset OCD, and is a risk factor for these groups (See Table 3). 
Table I The Results of Single-Site Allele Association Analysis for the Overall, Male, Female, Early-Onset, and Late-Onset OCD Samples

\begin{tabular}{|c|c|c|c|c|c|c|c|}
\hline SNP & Group & No & Allele & & OR (95\% Cl) & $x^{2}$ & $\mathbf{P}$ \\
\hline rs10491734 & $\begin{array}{l}\text { overall OCD } \\
\text { control } \\
\text { male OCD } \\
\text { male control } \\
\text { female OCD } \\
\text { female control } \\
\text { early onset OCD } \\
\text { control } \\
\text { late onset OCD } \\
\text { control }\end{array}$ & $\begin{array}{l}438 \\
465 \\
260 \\
276 \\
178 \\
189 \\
252 \\
465 \\
186 \\
465\end{array}$ & $\begin{array}{l}A(0.212) \\
0.231 \\
A(0.214) \\
0.250 \\
A(0.208) \\
0.201 \\
A(0.221) \\
0.230 \\
A(0.199) \\
0.230\end{array}$ & $\begin{array}{l}G(0.788) \\
0.769 \\
G(0.786) \\
0.750 \\
G(0.792) \\
0.799 \\
G(0.779) \\
0.770 \\
G(0.801) \\
0.770\end{array}$ & $\begin{array}{l}0.89(0.7 I-I .12) \\
0.82(0.62-I .09) \\
1.04(0.72-I .49) \\
0.95(0.73-I .23) \\
0.83(0.62-I .12)\end{array}$ & $\begin{array}{l}0.994 \\
1.909 \\
0.052 \\
0.150 \\
1.499\end{array}$ & $\begin{array}{l}0.319 \\
0.167 \\
0.819 \\
0.698 \\
0.221\end{array}$ \\
\hline rs37804I2 & $\begin{array}{l}\text { overall OCD } \\
\text { control } \\
\text { male OCD } \\
\text { male control } \\
\text { female OCD } \\
\text { female control } \\
\text { early onset OCD } \\
\text { control } \\
\text { late onset OCD } \\
\text { control }\end{array}$ & $\begin{array}{l}438 \\
465 \\
260 \\
276 \\
178 \\
189 \\
252 \\
465 \\
186 \\
465\end{array}$ & $\begin{array}{l}A(0.75 I) \\
0.77 I \\
A(0.754) \\
0.76 I \\
A(0.747) \\
0.788 \\
A(0.782) \\
0.772 \\
A(0.710) \\
0.772\end{array}$ & $\begin{array}{l}G(0.249) \\
0.229 \\
G(0.246) \\
0.239 \\
G(0.253) \\
0.212 \\
G(0.218) \\
0.228 \\
G(0.290) \\
0.228\end{array}$ & $\begin{array}{l}0.89(0.72-1 . \mathrm{I}) \\
0.96(0.73-1.27) \\
0.79(0.56-1.12) \\
\text { I.06 (0.8I-I.37) } \\
0.72(0.55-0.95)\end{array}$ & $\begin{array}{l}0.976 \\
0.071 \\
1.746 \\
0.177 \\
5.575\end{array}$ & $\begin{array}{l}0.323 \\
0.789 \\
0.186 \\
0.674 \\
0.018^{*}\end{array}$ \\
\hline rs30I434 & $\begin{array}{l}\text { overall OCD } \\
\text { control } \\
\text { male } O C D \\
\text { male control } \\
\text { female OCD } \\
\text { female control } \\
\text { early onset OCD } \\
\text { control } \\
\text { late onset OCD } \\
\text { Control }\end{array}$ & $\begin{array}{l}438 \\
465 \\
260 \\
276 \\
178 \\
189 \\
252 \\
465 \\
186 \\
465\end{array}$ & $\begin{array}{l}A(0.852) \\
0.878 \\
A(0.850) \\
0.884 \\
A(0.854) \\
0.870 \\
A(0.857) \\
0.878 \\
A(0.844) \\
0.878\end{array}$ & $\begin{array}{l}G(0.148) \\
0.122 \\
G(0.150) \\
0.116 \\
G(0.146) \\
0.130 \\
G(0.143) \\
0.122 \\
G(0.156) \\
0.122\end{array}$ & $\begin{array}{l}0.79(0.6 \mathrm{I}-\mathrm{I} .04) \\
0.74(0.52-1.06) \\
0.87(0.57-1.32) \\
0.83(0.60-1.14) \\
0.75(0.53-1.05)\end{array}$ & $\begin{array}{l}2.802 \\
2.702 \\
0.417 \\
1.326 \\
2.757\end{array}$ & $\begin{array}{l}0.094 \\
0.100 \\
0.518 \\
0.249 \\
0.097\end{array}$ \\
\hline rs3087879 & $\begin{array}{l}\text { overall OCD } \\
\text { control } \\
\text { male OCD } \\
\text { male control } \\
\text { female OCD } \\
\text { female control } \\
\text { early onset OCD } \\
\text { control } \\
\text { late onset OCD } \\
\text { Control }\end{array}$ & $\begin{array}{l}438 \\
465 \\
260 \\
276 \\
178 \\
189 \\
252 \\
465 \\
186 \\
465\end{array}$ & $\begin{array}{l}C(0.113) \\
0.119 \\
C(0.121) \\
0.107 \\
C(0.101) \\
0.135 \\
C(0.099) \\
0.118 \\
C(0.132) \\
0.118\end{array}$ & $\begin{array}{l}G(0.887) \\
0.881 \\
G(0.879) \\
0.893 \\
G(0.899) \\
0.865 \\
G(0.901) \\
0.882 \\
G(0.868) \\
0.882\end{array}$ & $\begin{array}{l}0.94(0.70-1.25) \\
1.15(0.79-1.68) \\
0.72(0.46-1.14) \\
0.82(0.58-1.17) \\
1.13(0.78-1.62)\end{array}$ & $\begin{array}{l}0.177 \\
0.541 \\
2.004 \\
1.199 \\
0.448\end{array}$ & $\begin{array}{l}0.674 \\
0.462 \\
0.157 \\
0.273 \\
0.503\end{array}$ \\
\hline
\end{tabular}

Note: *p-value $<0.05$ indicated significant statistical differences.

In conclusion, we found that the genotype of SLC1A1 rs301434 is significantly associated with all OCD and control groups, early-onset OCD and control groups, late-onset OCD and control groups as well as male OCD and control groups. The genotype and allele of $r s 3780412$ is significantly associated with late-onset 
Table 2 The Results of Single-Site Genotype Association Analysis for the Overall, Male, Female, Early-Onset, and Late-Onset OCD Samples

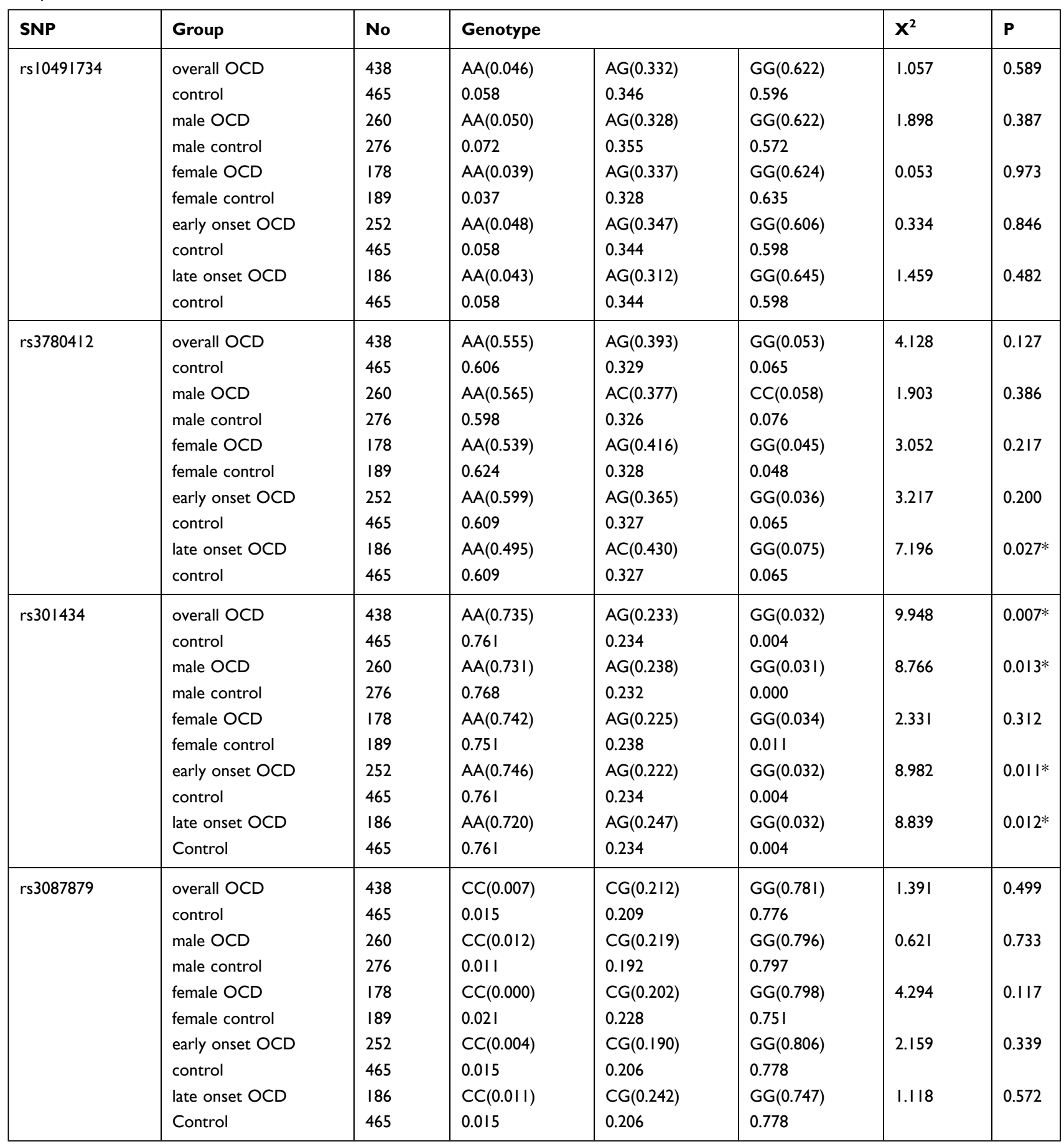

Note: ${ }^{p}$-value $<0.05$ indicated significant statistical differences.

OCD and control groups. The haplotypes (G-A-A-G, G-G-A-G) are associated with total OCD and control groups. Haplotype (G-G-A-G) is associated with female OCD, haplotype (G-A-G-G) is associated with male OCD, and haplotype (G-A-A-G, G-G-A-G) is associated with late-onset OCD. Our findings support the idea that SLC1A1 is a susceptibility gene for OCD, but this study also has limitations, due to the limited sample size, our results need to further increase the sample data for verification. 
Table 3 The Results of the Haplotype Analysis for SNP rs 1049I734-rs37804I2-rs301434-rs3087879 in OCD Patients and Controls

\begin{tabular}{|l|l|l|l|l|l|l|}
\hline Haplotype $^{\mathbf{a}}$ & Group & Case (Frequency, \%) & Control (Frenquency, \%) & $\mathbf{X}^{\mathbf{2}}$ & $\mathbf{P}$ & $\mathbf{O R}(\mathbf{9 5 \%} \mathbf{C I})$ \\
\hline \multirow{2}{*}{ GGAG } & All OCD & $100.59(0.115)$ & $77.22(0.083)$ & 4.707 & 0.030 & $1.412[1.033 \sim 1.930]$ \\
& Late-onset OCD & $46.64(0.125)$ & $77.03(0.083)$ & 5.040 & 0.024 & $1.552[1.055 \sim 2.283]$ \\
& Female OCD & $44.69(0.126)$ & $29.39(0.078)$ & 4.243 & 0.039 & $1.670[1.021 \sim 2.730]$ \\
\hline \multirow{2}{*}{ GAGG } & Male OCD & $59.52(0.115)$ & $38.21(0.069)$ & 6.578 & 0.010 & $1.737[1.134 \sim 2.660]$ \\
\hline \multirow{2}{*}{ GAAG } & All OCD & $403.99(0.462)$ & $468.24(0.503)$ & 4.536 & 0.033 & $0.815[0.675 \sim 0.984]$ \\
& Late-onset OCD & $165.67(0.445)$ & $469.92(0.505)$ & 5.439 & 0.019 & $0.748[0.585 \sim 0.955]$ \\
\hline
\end{tabular}

Note: Haplotypes with frequency $<0.03$ are ignored in analysis.

\section{Acknowledgments}

The authors wish to thank the patients, healthy volunteers, and their family members.

\section{Disclosure}

All authors declare no conflicts of interest for this work.

\section{References}

1. Fontenelle LF, Mendlowicz MV, Versiani M. The descriptive epidemiology of obsessive-compulsive disorder. Prog Neuropsychopharmacol Biol Psychiatry. 2006;30(3):327-337. doi:10.1016/j.pnpbp.2005.11.001

2. Ruscio AM, Stein DJ, Chiu WT, Kessler RC. The epidemiology of obsessive-compulsive disorder in the National Comorbidity Survey Replication. Mol Psychiatry. 2010;15(1):53-63. doi:10.1038/ mp.2008.94

3. Leckman JF, Goodman WK, Anderson GM, et al. Cerebrospinal fluid biogenic amines in obsessive compulsive disorder, Tourette's syndrome, and healthy controls. Neuropsychopharmacology. 1995;12 (1):73-86. doi:10.1038/sj.npp.1380241

4. Nutt D, Malizia A. Anxiety and OCD - the chicken or the egg? $J$ Psychopharmacol. 2006;20(6):729-731. doi:10.1177/026988 1106068424

5. Kwon JS, Joo YH, Nam HJ, et al. Association of the glutamate transporter gene SLC1A1 with atypical antipsychotics-induced obsessive-compulsive symptoms. Arch Gen Psychiatry. 2009;66 (11):1233-1241. doi:10.1001/archgenpsychiatry.2009.155

6. Rosenberg DR, Benazon NR, Gilbert A, Sullivan A, Moore GJ. Thalamic volume in pediatric obsessive-compulsive disorder patients before and after cognitive behavioral therapy. Biol Psychiatry. 2000;48(4):294-300. doi:10.1016/s0006-3223(00)00902-1

7. Arnold PD, Sicard T, Burroughs E, Richter MA, Kennedy JL. Glutamate transporter gene SLC1A1 associated with obsessive-compulsive disorder. Arch Gen Psychiatry. 2006;63 (7):769-776. doi:10.1001/archpsyc.63.7.769

8. Dickel DE, Veenstra-VanderWeele J, Cox NJ, et al. Association testing of the positional and functional candidate gene SLC1A1/ EAAC1 in early-onset obsessive-compulsive disorder. Arch Gen Psychiatry. 2006;63(7):778-785. doi:10.1001/archpsyc.63.7.778

9. Wendland JR, Moya PR, Timpano KR, et al. A haplotype containing quantitative trait loci for SLC1A1 gene expression and its association with obsessive-compulsive disorder. Arch Gen Psychiatry. 2009;66 (4):408-416. doi:10.1001/archgenpsychiatry.2009.6

10. Rajendram R, Kronenberg S, Burton CL, Arnold PD. Glutamate genetics in obsessive-compulsive disorder: a review. J Can Acad Child Adolesc Psychiatry. 2017;26(3):205-213.
11. Bhattacharyya S, Khanna S, Chakrabarty K, Mahadevan A, Christopher R, Shankar SK. Anti-brain autoantibodies and altered excitatory neurotransmitters in obsessive-compulsive disorder. Neuropsychopharmacology. 2009;34(12):2489-2496. doi:10.1038/ npp.2009.77

12. Nissen JB, Thomsen PH. Clinicians' views on clinical examination and treatment of children and adolescents with obsessive-compulsive disorder (OCD). A Danish national survey study. Nord J Psychiatry. 2008;62(4):309-314. doi:10.1080/08039480801984065

13. Sassaroli S, Lauro LJ, Ruggiero GM, Mauri MC, Vinai P, Frost R. Perfectionism in depression, obsessive-compulsive disorder and eating disorders. Behav Res Ther. 2008;46(6):757-765. doi:10.1016/j. brat.2008.02.007

14. Menzies L, Chamberlain SR, Laird AR, Thelen SM, Sahakian BJ, Bullmore ET. Integrating evidence from neuroimaging and neuropsychological studies of obsessive-compulsive disorder: the orbitofronto-striatal model revisited. Neurosci Biobehav Rev. 2008;32(3):525-549. doi:10.1016/j.neubiorev.2007.09.005

15. Kanai Y, Hediger MA. The glutamate/neutral amino acid transporter family SLC1: molecular, physiological and pharmacological aspects. Pflugers Arch. 2004;447(5):469-479. doi:10.1007/s00424-003-1146-4

16. Samuels J, Wang Y, Riddle MA, et al. Comprehensive family-based association study of the glutamate transporter gene SLC1A1 in obsessive-compulsive disorder. Am J Med Genet B Neuropsychiatr Genet. 2011;156B(4):472-477. doi:10.1002/ajmg.b.31184

17. Shugart YY, Wang Y, Samuels JF, et al. A family-based association study of the glutamate transporter gene SLC1A1 in obsessive-compulsive disorder in 378 families. Am J Med Genet B Neuropsychiatr Genet. 2009;150B(6):886-892. doi:10.1002/ajmg. b.30914

18. Stewart SE, Fagerness JA, Platko J, et al. Association of the SLC1A1 glutamate transporter gene and obsessive-compulsive disorder. $\mathrm{Am}$ $J$ Med Genet B Neuropsychiatr Genet. 2007;144B(8):1027-1033. doi:10.1002/ajmg.b.30533

19. Nieoullon A, Canolle B, Masmejean F, Guillet B, Pisano P, Lortet S. The neuronal excitatory amino acid transporter EAAC1/EAAT3: does it represent a major actor at the brain excitatory synapse? J Neurochem. 2006;98(4):1007-1018. doi:10.1111/j.1471-4159.2006.03978.x

20. Bellini S, Fleming KE. Neuronal glutamate transporters control dopaminergic signaling and compulsive behaviors.. 2018;38(4):937-961. doi:10.1523/jneurosci.1906-17.2017

21. Goodman WK, Price LH, Rasmussen SA, et al. The Yale-Brown Obsessive Compulsive Scale. I. Development, use, and reliability. Arch Gen Psychiatry. 1989;46(11):1006-1011. doi:10.1001/ archpsyc. 1989.01810110048007

22. Nurnberger JI Jr, Blehar MC, Kaufmann CA, et al. Diagnostic interview for genetic studies. Rationale, unique features, and training. NIMH Genetics Initiative. Arch Gen Psychiatry. 1994;51(11):849-859; discussion 863-844. doi:10.1001/archpsyc.1994.03950 110009002 
23. Li Z, Zhang Z, He Z, et al. A partition-ligation-combinationsubdivision EM algorithm for haplotype inference with multiallelic markers: update of the SHEsis. Cell Res. 2009;19(4):519-523. doi: $10.1038 /$ cr.2009.33

24. de Salles Andrade JB, Giori IG, Melo-Felippe FB, Vieira-Fonseca T, Fontenelle LF, Kohlrausch FB. Glutamate transporter gene polymorphisms and obsessive-compulsive disorder: a case-control association study. $J$ Clin Neurosci. 2019;62:53-59. doi:10.1016/j. jocn.2019.01.009
25. Wu H, Wang X, Xiao Z, et al. Association between SLC1A1 gene and early-onset OCD in the Han Chinese population: a case-control study. J Mol Neurosci. 2013;50(2):353-359. doi:10.1007/s12031013-9995-6

\section{Publish your work in this journal}

Neuropsychiatric Disease and Treatment is an international, peerreviewed journal of clinical therapeutics and pharmacology focusing on concise rapid reporting of clinical or pre-clinical studies on a range of neuropsychiatric and neurological disorders. This journal is indexed on PubMed Central, the 'PsycINFO' database and CAS, and is the official journal of The International Neuropsychiatric Association (INA). The manuscript management system is completely online and includes a very quick and fair peer-review system, which is all easy to use. Visit http://www.dovepress.com/testimonials.php to read real quotes from published authors. 